\title{
The current state of the management of the upper limb in tetraplegia
}

\author{
D W Lamb FRCSE \\ President, International Federation of Societies For Surgery of the Hand, The Royal \\ College of Surgeons, Edinburgh, Scotland.
}

When Paraplegia was introduced in 1962, there was very little in the medical literature about the surgical management of the upper limbs in traumatic tetraplegia. There were several reasons for this including the relative rarity of cervical spine injuries in comparison to those of the thoraco-lumbar region and the resultant concentration on the demanding needs of the paraplegic. Those patients sustaining cervical cord damage were unlikely to survive, and there was little stimulus to improve upper limb function.

One of the first references to reconstructive surgery in the upper limbs of the tetraplegic was by Lipscomb and his colleagues from the Mayo Clinic in $1958 .^{1}$

The reviewer spent the following year (1959) in the stimulating atmosphere of the Rancho Los Amigos Hospital in Los Angeles, where a very sophisticated programme of upper limb bracing for the paralysed upper limb was in progress. ${ }^{2}$ Armed with this experience and stimulated by Lipscomb's article, a programme of upper limb management in the tetraplegic was started at the newly developed Spinal Injury Unit at Edenhall Hospital, Edinburgh to compare the benefits to upper limb function from bracing or surgical reconstruction. ${ }^{3}$

In the past 20 years, there has been not only an increasing number of cervical cord injuries, but the standard of early management of the patient has so improved that most of the victims, usually young adults, will survive to be confined permanently to a wheelchair for a life of 20-30 years.

Cervical cord injury is now the commonest cause of severe bilateral upper limb paralysis in the western world and in many areas of the world there is a large group of young people left with impaired upper limb ability for activities of daily living. It is incumbent upon those responsible for their care that every effort be made to improve movement and control of the arms and to provide grasp and release of objects in the hand.

The increasing importance of this aspect of the overall care of the tetraplegic patient has been recognised in recent years by a group of surgeons around the world devoted to the practice of reconstructive surgery of the upper limb and hand. ${ }^{4-10}$

This increasing interest in improving upper limb function for the tetraplegic, which is not yet fully reflected in the overall management of the tetraplegic in many spinal units, has resulted in four international conferences (Edinburgh, Scotland 1979; Giens, France 1984; Gothenburg, Sweden 1988; and Palo Alto, California 1991). At this recent meeting, hosted by $\mathrm{Dr}$ Vincent R Hentz of Stanford University, there were 100 participants from 11 countries. The main emphasis of the meeting was to develop a standardised system for the evaluation of upper limb function. The methods of functional testing used in several of the centres represented at the meeting were described fully, but each of these was felt to be lacking in some aspect and a committee was set up to develop a standardised evaluation test for the tetraplegic patient. The possible results of reconstructive surgery were demonstrated in a striking manner in several video tapes and the value of video recording before and after surgery was emphasised and is probably the best way of assessing the function of the upper limbs in the individual patient.

A newsletter for those interested in the care and functional improvement of the upper limbs of patients with tetraplegia has recently been started, and will be organised by Dr William L Mulbry Jr MD (Hand 
Surgery Centre of Charleston, PA, 1 Poston Road, Suite 200, Charleston, South Carolina 29407, USA) who would like to hear from those involved in this work.

Zancolli ${ }^{6}$ found that three-quarters of the patients under his supervision came into the group with sparing of the C6 cervical segment, but paralysis from the seventh segment downwards. This is the commonest clinical pattern in tetraplegia and such patients are unable to straighten the elbow actively and have no active control of the fingers and thumb.

Moberg ${ }^{4}$ showed the tremendous value to the tetraplegic patient by restoring active extension of the elbow, utilising transfer of the posterior third of the deltoid muscle into the triceps. Elbow extension against gravity enables the patient to have a much wider field of hand activity and in particular, the ability to elevate the arm over the head to put objects onto a peg or a shelf, and to reach out for objects without the elbow 'buckling'. Lamb and $\mathrm{Chan}^{8}$ found that all patients reviewed in their series who had had the Moberg procedure on one elbow requested that the same should be done to the other.

The other main functional loss of active digital flexion and an inability to grasp can be restored by tendon transfers to give a good grasp and release of objects from the hand. ${ }^{3-6,8,11-15}$

There is no doubt that great improvement in upper limb function can follow carefully performed surgery in carefully selected patients which will far outweigh the functional benefits attained from orthoses.

It is essential that contractures of the upper limb joints should not be allowed to develop if surgery is to be successful and the presence of spasticity will also affect the result adversely. Moberg ${ }^{4}$ has stressed the importance of sensation including proprioception in the hand before good hand function can be restored by tendon transfer. Careful testing by the 2 point discrimination to a level of $10-12 \mathrm{~mm}$ will give good proprioception which is dependent on the skin receptors.

Good results from surgery will depend very much upon the stimulation and encouragement which the patient receives after tendon transfers from an enthusiastic and skilful therapist. Provided that the patient is well motivated and not expecting too much, the results following surgery are gratifying because the activities of daily living are so improved that a greater enjoyment of life is provided.

For many years experimental work on neuromuscular stimulation by implanted electrodes has been carried out at the Case Western Reserve University, Cleveland and at other centres. At the recent meeting in Palo Alto, Keith, Peckham, Stroh and Creasey reported from Cleveland on their present progress with regard to the clinical application to the tetraplegic patient of these techniques. The current technique utilises percutaneous implanted electrodes employing an 8-channel stimulator with an external controller unit usually shoulder mounted. The aim is to provide both lateral and palmar prehension. Twenty-eight systems have been implanted with the longest in use now for 12 years.

They state that the next generation of functional neuromuscular stimulation systems will involve a totally implantable system with the additional aim of providing some sensory feedback in the C5 dermatome.

It is likely that future developments will combine both neuromuscular electrical stimulation and tendon transfer, and present the exciting prospect of greatly improving the overall upper limb function of the tetraplegic.

\section{References}

1 Lipscomb BR, Elkins EC, Henderson ED (1958) Tendon transfers to restore function of hands in tetraplegia. J Bone Joint Surg 40A: 1071-1080.

2 Nickel BL, Perry J, Garrett AL (1963) Development of useful function in severely paralysed hands. J Bone Joint Surg 45A: 933.

3 Lamb DW (1965) The management of upper limbs in cervical cord injuries. In: Harris P, ed. Spinal Injuries. Proceedings of a symposium at The Royal College of Surgeons, Edinburgh, 1963: 120-127. 
4 Moberg E (1975) Surgical treatment for absent single hand grip and elbow extension in quadriplegia. $J$ Bone Joint Surg 57A: 196.

5 Moberg E (1978) The Upper Limb in Tetraplegia. A New Approach to Surgical Rehabilitation. Thieme, Stuttgart.

6 Zancolli E (1975) Surgery for the quadriplegia hand with strong wrist extension preserved. Clin Orthop 12: 101.

7 Lamb DW, Landry RM (1972) The hand in quadriplegia. Paraplegia 7: 118.

8 Lamb DW, Chan KM (1983) Surgical reconstruction of the upper limb in traumatic tetraplegia. J Bone Joint Surg 65B: 291.

9 Freehafer AA (1969) Care of the hand in cervical spinal cord injuries. Paraplegia 7: 118.

10 Freehafer AA (1975) Tendon transfer to improve grasp in patients with cervical spinal cord injury. Paraplegia 13: 15.

11 Lamb DW (1991) Reconstructive surgery of the upper limb and hand in traumatic tetraplegia. In: Lee BY, Ostrander LE, Cochrane Gvan B, Shaw WW, eds. The Spinal Cord Injured Patient. Comprehensive Management. WB Saunders Co, London.

12 Lamb DW (1989) The upper limb in tetraplegia. Seminars Orthop 4(1) (March): 43-48.

13 Beasley RW (1983) Surgical treatment of hands for C5 and C6 tetraplegia. Orthop Clin North Am 14 : 893.

14 House JH, Gwathmey LW, Lundsgaard DK (1976) Restoration of strong grasp and lateral pinch in tetraplegia due to cervical spinal cord injury. J Hand Surg 1: 152.

15 Hentz BR, Brown M, Keoshian LA (1983) Upper limb reconstruction in quadriplegia: functional assessment and proposed treatment modifications. J Hand Surg 8: 119-130. 